\title{
Using Language as a Transparent Resource in the Teaching and Learning of Mathematics in a Grade 11 Multilingual Classroom
}

\author{
Mamokgethi Setati \\ University of South Africa \\ setatrm@unisa.ac.za
}

\author{
Terence Molefe \\ Fons Luminus High School \\ molefebt@yahoo.com
}

\author{
Mampho Langa \\ Oprah Winfrey Leadership \\ Academy for Girls \\ Mampho.Langa@owla.co.za
}

In this paper, we draw on a study conducted in Grade 11 classrooms to explore how the learners' home languages can be used for teaching and learning mathematics in multilingual classrooms in South Africa. This report is part of a wider study that is still in progress. Based on an analysis of data collected through lesson observations in a Grade 11 class and learner interviews we argue for the deliberate, proactive and strategic use of the learners' home languages as a transparent resource in the teaching and learning of mathematics in multilingual classrooms. Such use of the languages will ensure that learners gain access to mathematical knowledge without losing access to English, which many parents, teachers and learners presently see as a necessary condition for gaining access to social goods such as higher education and employment.

What does it mean to teach or learn mathematics in a language that is not your home, first or main language? This is the situation in the majority of classrooms in South Africa. In these classrooms the language of learning and teaching (LoLT) is English - one of the eleven official languages; however, neither the teacher nor the learners have English as their main, home or first language. Research shows that teachers and learners in these classrooms prefer that English be used as the LoLT (Setati, in press). In addition to this, anecdotal evidence shows that a majority of learners in these classrooms are not motivated to study mathematics, and they are doing it either because they have to or because they know that it is needed for any higher education study related to science, technology or commerce. What strategies are appropriate for use in these classrooms? Embedded in this question are issues about language and learning and also about motivating learners' interest in mathematics.

In this paper we draw on a wider study exploring relevant pedagogies for teaching and learning mathematics in multilingual classrooms. We specifically focus on data collected in one Grade 11 classroom to explore how the learner's home languages can be used as a transparent resource in the teaching and learning of mathematics in multilingual classrooms.

We begin the paper with a review of research on teaching and learning mathematics in multilingual classrooms. Through this we expose three prevalent dichotomies in research on teaching and learning mathematics in multilingual classrooms. First, is the dichotomy between using English as LoLT as opposed to using the learners' home language(s) as LoLT. Second, is the dichotomy about drawing on socio-political perspectives when analysing interactions in multilingual mathematics classrooms as opposed to drawing on cognitive perspectives. The third dichotomy is about gaining access to mathematical knowledge as opposed to access to English.

We then discuss the theory that informed the analysis we present in the paper. This discussion provides a theoretical background for the argument for the deliberate, proactive and strategic use of the learners' home languages as a transparent resource in the teaching and learning of mathematics. 


\section{Teaching and learning mathematics in multilingual classrooms}

There is a continuing debate in South African education and the public domain regarding which language should be used for teaching mathematics in multilingual classrooms in which children are still learning English. This debate is due to the fact that learners in many of these classrooms are not yet fully fluent in English which is the LoLT in their classrooms.

While the South African language in education policy (LiEP) encourages multilingualism (Department of Education, 1997) and research supports the use of the learners' home languages (Moschkovich, 2002), a recent analysis of the learners' and teachers' language choices for teaching and learning mathematics shows a preference for English (Setati, in press). In this analysis Setati argues that the desire to gain access to social goods (e.g. jobs, higher education) overrides the multilingual teachers' and learners' concern for epistemological access. The view with many teachers and learners is that English is an international language and in South Africa it is important for higher education, jobs and subsequently a better life.

Given this background, we argue that it is crucial to explore ways of drawing on the learners' home languages for teaching and learning mathematics in multilingual classrooms without denying them access to English. Previous research argues that the learners' home languages are a resource for mathematics learning (Adler, 2001; Moschkovich, 1999; Setati, 2005; Setati \& Adler, 2000). The challenge, however, is that in a context such as South Africa, where the hegemony of English is so prevalent, regarding the learners' home languages as a resource tends to be seen as a threat to multilingual learners' development of fluency in English. As Sachs (1994) pointed out, in South Africa "all language rights are rights against English" (p. 1). Hence our argument that for the use of the learners' home languages in the teaching and learning of mathematics in multilingual classrooms to be successful it must ensure that the learners gain epistemological access without losing access to English. Granville et al. (1998) present a similar idea in relation to the South African language in education policy, where they argue for English without $\mathrm{g}(\mathrm{u})$ ilt. What is new about our argument is the different orientation we bring by focusing on learning and teaching rather than policy.
Debates around language and learning in South Africa tend to create a dichotomy between learning in English and learning in the home languages. They create an impression that the use of the learners' home languages for teaching and learning must necessarily exclude and be in opposition to English, and the use of English must necessarily exclude the learners' home languages. In an article entitled 'Why don't kids learn maths and science successfully?', Sarah Howie of the University of Pretoria is quoted as saying "The most significant factor in learning science and maths isn't whether the learners are rich or poor. It's whether they are fluent in English" (Science in Africa, 2003). This she said drawing on her analysis of South Africa's poor performance in the Third International Mathematics and Science Study of 1995 (see also Howie 2003, 2004). In the same article Howie makes an impassioned call on South Africa to choose only one language for teaching and learning mathematics in multilingual classrooms:

Let's stop sitting on the fence and make a hard decision. We must either shore up the mother tongue teaching of maths and sciences, or switch completely to English if we want to succeed.

Our argument in this paper is that in a multilingual country such as South Africa the choices are not as simplistic as Howie suggests. Our argument is informed by a holistic view of multilingual learners (different from Howie's monolingual view), in our view multilingual learners have a unique and specific language configuration and therefore they should not be considered as the sum of two or more complete or incomplete monolinguals. To explain this different but complete language system in multilinguals, Grosjean (1985) uses an analogy from the domain of athletics:

The high hurdler blends two types of competencies: that of high jumping and that of sprinting. When compared individually with the sprinter or the high jumper, the hurdler meets neither level of competence, and yet when taken as a whole, the hurdler is an athlete in his or her own right. No expert in track and field would ever compare a high hurdler to a sprinter or to a high jumper, even though the former blends certain characteristics of the latter two. In many ways the bilingual is like the high hurdler. (p. 471) 
The use of the learners' home languages as a transparent resource that we are exploring in this paper is informed by this holistic view of multilingual learners. We accept that the idea of drawing on the learners' home languages during teaching is not necessarily new. The use of codeswitching as a learning and teaching resource in bilingual and multilingual mathematics classrooms has been the focus of research in the recent past (e.g. Adendorff, 1993; Adler, 1998, 2001; Arthur, 1994; Khisty, 1995; Merritt, Cleghorn, Abagi, \& Bunyi, 1992; Moschkovich, 1996, 1999; Ncedo, Peires, \& Morar, 2002; Setati, 1998; Setati, 2005; Setati \& Adler, 2000). These studies have argued for the use of the learners' home languages in teaching and learning mathematics, as a support needed while learners continue to develop proficiency in the LoLT at the same time as learning mathematics. All of these studies seem to be in agreement that to facilitate multilingual learners' participation and success in mathematics teachers should recognise their home languages as legitimate languages of mathematical communication. The practical manifestation of the use of the learners' home languages in these studies is through code-switching, mainly to provide explanation to learners in their home languages. In all of these studies code-switching is presented as spontaneous and reactive, the learner's home languages are only used in oral communication and never in written texts. What we are advocating in this paper is the deliberate, strategic and proactive use of the learners' home languages. This strategy recognizes the fact that learners want access to English and thus while we draw on the learners' home languages and foreground the quality of the mathematics tasks used during teaching, we also ensure that English is still available to learners and they can continue to develop fluency in it.

Research into the complex relationship between bilingualism/multilingualism and mathematics teaching and learning argues that bilingualism/multilingualism per se does not impede mathematics learning (Clarkson, 1991; Dawe, 1983; Stephens, Waywood, Clarke, \& Izard, 1993; Zepp, 1989). This field of research has been criticised because of its cognitive orientation and its inevitable deficit model of the bilingual learner (Martin-Jones \& Romaine, 1986; Frederickson \& Cline, 1990; both in Baker, 1993). Learner performance (and by implication, mathematical achievement) is determined by a complex set of inter-related factors. Poor performance by multilingual learners thus cannot be attributed to the learners' limited language proficiencies in isolation from the wider social, cultural and political factors that infuse schooling.

In our view, this past research informed by a cognitive perspective presents an implicit argument in support of the maintenance of learners' home languages, and of the potential benefits of learners using their home language(s) as a resource in their mathematics learning. Multilingualism is the norm in many South African classrooms, rather than the exception. Hence the need for South African mathematics education not only to treat the multilingual learner as the norm but also to view his or her facility across languages as a resource rather than a problem (Baker, 1993). Through our work in this study we have come to recognise that separating cognitive matters from the socio-political issues relating to language and power when exploring the use of language(s) for teaching and learning mathematics in multilingual classrooms is not productive. While we accept that cognitively oriented research does not deal with the socio-political issues relating to the context in which teaching and learning takes place, we acknowledge that it is useful in helping us attend to issues relating to the quality of the mathematics and its teaching and learning in multilingual classrooms. In this study we are thus moving against dichotomies, not only of language choices but also of theoretical perspectives.

\section{Theoretical underpinnings}

This study is broadly informed by an understanding of language as "a transparent resource" (Lave \& Wenger, 1991). While the notion of transparency as used by Lave and Wenger is not usually applied to language as a resource nor to learning in school, it is illuminating of language use in multilingual classrooms (see also Adler, 2001). Lave and Wenger (1991) argue that access to a practice relates to the dual visibility and invisibility of its resources:

Invisibility is in the form of unproblematic interpretation and integration into activity, and visibility is in the form of extended access to information. This is not a dichotomous distinction, since these two crucial characteristics are in a complex interplay, their relation being one of both conflict and synergy. (p. 103)

For language in the classroom to be useful it must be both visible and invisible: visible so that it is clearly seen and understood by all; and invisible in 
that when interacting with written texts and discussing mathematics, this use of language should not distract the learners' attention from the mathematical task under discussion but facilitate their mathematics learning. This idea is similar to the use of technology in mathematics learning. The technology needs to be visible so that the learners can notice and use it. However it also needs to be simultaneously invisible so that the learners' attention is focussed on the mathematics problem that they are trying to solve. Like technology, language needs to be a transparent resource. As Lave and Wenger argue the idea of the visibility and invisibility of a resource is not a dichotomous distinction, it is not about whether to focus on language or mathematics, it is about recognising that the two are intertwined and are constantly in complex interplay.

We found Lave and Wenger's concept of transparency useful in conceptualising a strategy for using language in teaching and learning mathematics in multilingual classrooms. Multilingual classrooms are characterised by complex multiple teaching demands: the learners' limited proficiency in the language of learning and teaching (English); the challenge to develop the learners' mathematical proficiency as well as the presence of multiple languages. The strategy we are exploring is guided by two main principles, which are informed by the theoretical assumptions elaborated in the discussion above. First, it is the deliberate use of the learners' home languages. We emphasise the word deliberate because with this strategy the use of the learners' home languages is deliberate, proactive and strategic and not spontaneous and reactive as it happens with codeswitching. Second, is that through the selection of real world interesting and challenging mathematical tasks, learners would develop a different orientation towards mathematics than they had and would be more motivated to study and use it (Gutstein, 2003). Many learners in multilingual classrooms in South Africa have what Gutstein (2003) describes as "the typical and well documented disposition with which most mathematics teachers are familiar - mathematics as a rote-learned, decontextualised series of rules and procedures to memorise, regurgitate and not understand" (p. 46). In this study we selected high cognitive demand tasks (Stein, Smith, Henningsen, \& Silver, 2000), that present real world problems that the learners can find interesting and useful to engage with.

\section{The study}

The study presented in this paper was undertaken in a Grade 11 class taught by Terence, the second author. The data we are presenting here was collected in Terence's classroom in a multilingual high school in Soweto, Johannesburg. There were 36 learners in his class and they had the following home languages: Setswana, Xitsonga, IsiZulu and Tshivenda. Each of the learners was able to communicate in at least four languages and they were learning English as a subject at second language level as well as their respective home languages as subjects at first language level. Terence is multilingual and fluent in eight languages ${ }^{1}$, which includes all the home languages of his learners as well as English. His home language is Setswana. At the time of the study Terence had been teaching mathematics at secondary school level for 15 years.

Data was collected through lesson observations and individual learner interviews. Lessons were observed and video recorded for four consecutive days. At the end of the four days four learners from different home language groups were interviewed by Mampho, the third author and a former teacher in the school who was not present during lesson observations. The interview focused on their reflections and views about the lessons.

On the next page is the task that the learners were working on during the lessons observed and analysed in this paper. This task was translated into the four home languages of the learners in the class.

During the lessons learners were organised into seven home language groups: two Setswana groups, two Tshivenda groups, two IsiZulu groups and one Xitsonga group. Six of the groups had five learners and one group had six learners and they were given tasks in two language versions (English and their home language). Learners were explicitly made aware of the two language versions of the task and encouraged to communicate in any language including their home languages at any stage during the lessons.

All the lessons and learner interviews were video recorded and then transcribed. To analyse the video-recording and the transcribed data we looked

\footnotetext{
${ }^{1}$ This kind of multilingualism is not unusual. Given the integration of different ethnic groups, a majorty of African teachers (indeed African people in general) in the Gauteng province are multilingual and can communicate in at least four languages.
} 


\section{COST OF ELECTRICITY}

The Brahm Park electricity department charges R40,00 monthly service fees then an additional 20c per kilowatt-hour (kWh). A kilowatt-hour is the amount of electricity used in one hour at a constant power of one kilowatt.

1. The estimated monthly electricity consumption of a family home is $560 \mathrm{kWh}$. Predict what the monthly account would be for electricity.

2. Three people live in a townhouse. Their monthly electricity account is approximately R180,00. How many kilowatt-hours per month do they usually use?

3. In winter the average electricity consumption increases by $20 \%$, what would the monthly bills be for the family home in (1) above and for the townhouse?

4. In your opinion, what may be the reason for the increase in the average electricity consumption in (3) above?

5. Determine a formula to assist the electricity department to calculate the monthly electricity bill for any household. State clearly what your variables represent and the units used.

6. a) Complete the following table showing the cost of electricity in Rand for differing amounts of electricity used:

\begin{tabular}{|l|l|l|l|l|l|l|l|l|l|l|}
\hline Consumption (kWh) & 0 & 100 & 200 & 300 & 400 & 500 & 600 & 700 & 800 & 900 \\
\hline Cost (in Rand) & & & & & & & & & & \\
\hline
\end{tabular}

b) Draw a graph on the set of axes below to illustrate the cost of different units of electricity at the rate charged by the Brahm Park electricity department.

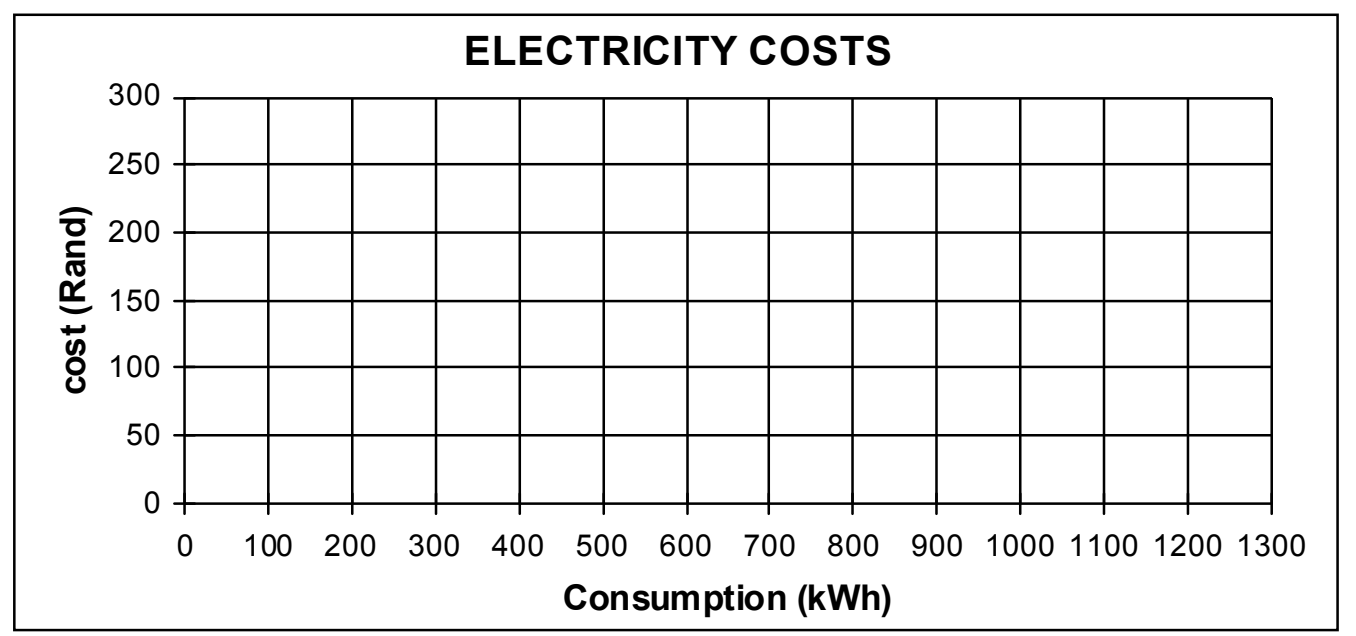

After careful consideration, the electricity department decided to alter their costing structure. They decide that there will no longer be a monthly service fee of R40,00 but now each kilowatt-hour will cost 25 c.

7. What would be the new monthly electricity accounts for the family home and the townhouse?

8. a) Complete the following table showing the cost of electricity in Rand for differing amounts of electricity used using the new costing structure:

\begin{tabular}{|l|l|l|l|l|l|l|l|l|l|l|}
\hline Consumption (kWh) & 0 & 100 & 200 & 300 & 400 & 500 & 600 & 700 & 800 & 900 \\
\hline Cost (in Rand) & & & & & & & & & & \\
\hline
\end{tabular}

b) Draw a graph on the same set of axes in question 6 b) to illustrate the cost of electricity for different units of electricity using the new costing structure.

9. Do both the family home and the townhouse benefit from this new costing structure? Explain.

10. If people using the electricity had the option of choosing either of the two costing structures, which would you recommend? Clearly explain your answer using tables you have completed and graphs drawn in questions 6 a) and 6 b) and 8 a) and 8 b) above.

Malati Materials (30-04-2005) 
for presences (what was visible) and absences (what was invisible) in what the learners were talking about. In the lesson observation data, what was most visible was learners' attempts to find the solutions to the questions in the task without much focus to the language. There was only one incident during the lessons observed, which we discuss in more detail below, where language became visible but not simultaneously invisible in one of the groups.

All the lessons and learner interviews were video recorded and then transcribed. To analyse the video-recording and the transcribed data we looked for presences (what was visible) and absences (what was invisible) in what the learners were talking about. In the lesson observation data, what was most visible was learners' attempts to find the solutions to the questions in the task without much focus to the language. There was only one incident during the lessons observed, which we discuss in more detail below, where language became visible but not simultaneously invisible in one of the groups. Language was, however, constantly visible for Terence, the teacher. For instance when asking learners to read he would specify which language they should read in. In the section that follows we discuss, with evidence from lesson observation data, incidents during the lessons when language was transparent (visible and invisible) and also when it was visible but not simultaneously invisible (i.e. not transparent).

\section{When language was visible and invisible}

In our analysis we found that when language was transparent learners' interactions were conceptual - learners' interactions were focused not only on what the solution is but also why it is correct. The two extracts we are analysing in this section happened in the Tshivenda group and are typical of how language functioned as a transparent resource during interactions between Terence and the learners and also between the learners themselves. Both extracts are taken from the first lesson at the time when the learners were beginning their work on the task and they needed to understand the following statement in the problem:

\section{The Brahm Park electricity department charges R40,00 monthly service fees then an additional 20c per kilowatt-hour ( $\mathrm{kWh}$ ). A kilowatt-hour is the amount of electricity used in one hour at a constant power of one kilowatt}

The extract below shows the interaction between Terence and the learners in the group. Here Terence is working with them on the two charges mentioned in the problem, the R40 monthly service fee and the additional 20c per kilowatt-hour.

1. Terence: Forty rhanda heyi, vhoibadhala when [When is the forty rand paid?]

2. Sipho: In a month.

3. Terence: Twenty cents yone [What about the twenty cents?]

4. Given: Twenty cents yo ediwa. [Twenty cents is added.]

5. Terence: Why i ediwa [Why is it added?]

6. Learners: (Silent).

7. Terence: Vhoi edela mini? Twenty cents vhoi edela mini [Why is it added? Why is twenty cents added?]

8. Learners: (Inaudible).

9. Terence: Okay, if you use electricity ukho bhadala forty rand? [Okay, if you use electricity will you pay forty rand?]

10. Learners: Yes meneer [sir]

11. Terence: If unga shumisanga electricity ukho bhadala forty rand [If you did not consume electricity, will you pay forty rand?]

12. Sipho: No, no no ...

13. Given: Haena, whether ushumisile ore haushumisanga, ukhobhadala forty rhanda [No, whether you have consumed electricity or not, you pay the forty rand.]

14. Terence: Whether ushumisile ore haushumisanga? [Whether consumed or not?]

15. Sipho: Eya, yes, it is a must.

16. Terence: It is a must?

One very noticeable thing about the extract above is the fact that it is in a mixture of English and the learners' home language (Tshivenda). This as indicated earlier was typical of interactions during the lessons observed in this class. The unproblematic move between Tshivenda and English without explicit negotiation between interactants is an indication that language is functioning as a transparent resource. Whilst it is visible it is also invisible enough to be used without distracting attention from the task. This invisibility of language as a mediating tool allows focus on and thus supports visibility of the mathematics the learners are discussing (Lave \& Wenger, 1991). At the same time, the visibility of language (i.e. tasks given in two languages) is necessary for allowing its unproblematic invisible use.

In the extract above, the learners are struggling to understand the phrase "an additional 20c per kilowatt-hour (kWh)". While they understand that everyone who has electricity is supposed to pay the R40 monthly cost and also that 20c is added, they seem to be having difficulty in understanding why the $20 \mathrm{c}$ is added. In utterances 5 to 7 Terence asks 
them why 20c was added. Seeing that they are not able to answer his question, he moves back to asking them about the R40 in utterance 9 . By doing this Terence is separating the R40 from the 20c so that the learners can see that while everyone who has electricity is required to pay $\mathrm{R} 40$, as to how much they pay thereafter depends on the amount of kilowatt hours they used and $1 \mathrm{kWh}$ costs $20 \mathrm{c}$. The extract above ends with Terence in utterance 16 having established with the learners that the R40 payment is a mandatory service fee for everyone who has electricity. In the extract below the learners carry on with the discussion (on their own) about when and why $20 \mathrm{c}$ is added.

17. Given: Hei, nayo ... ar ... (giggles) ... So forty rhanda hi monthly cost ne, then ba yieda nga twenty cents kha kilowatt for one hour. Then after that, angado shumisa ..., baibidza mini? Heyi ... ndoshumisa one kilowatt nga twenty cents kha one hour [Hey, this question ... ar ...(giggles) ... So forty rand is the monthly cost, then they add twenty cents per kilowatt-hour. ..., they use..., what do they call it? Hey ... they use one kilowatt-hour for twenty cents.]

18. Sipho: Eya [Yes]

19. Given: Boyieda, maybe boshumisa twenty cents nga one hour [They add it, maybe they use twenty cents per hour.]

20. Sipho: Eya, yantha [Yes, one hour]

21. Given: Iba ... [It becomes...]

22. Given and Sipho (together): Forty rand twenty cents.

23. Sipho: Yes, vhoibadela monthly, ngangwedzi ya hona. Yo fhelela, yes. Sesiyaqubheka. [Yes, they pay it monthly, each month. It is complete, yes. We continue.]

The transparent use of language continues in the above extract. The learners do not focus on what language is used for what; they are focused on communicating their understanding. This transparency of language enables conceptual interactions between the learners and the teacher and also among learners themselves. Using their home language, Tshivenda, as a legitimate language of interaction together with English made it possible for them to understand that in this case $1 \mathrm{kWh}$ costs $20 \mathrm{c}$. The learners are not concerned about the correctness of their grammar in Tshivenda and in English, they are more focused on gaining an understanding of the problem and having both language versions serves as a resource that they can draw as and when they need to.

In the next section we focus on the incident during lesson one, when language was not a transparent resource.

\section{When language was visible but not simultaneously invisible}

As indicated earlier when a resource is too visible it distracts attention from the subject matter. The extract below indicates learners in the Tshivenda group interacting with each other on the answer to questions 3 and 4 in the task sheet, which stated as follows:

3. In winter the average electricity consumption increases by $20 \%$, what would the monthly bills be for the family home in (1) above and for the townhouse?

4. In your opinion, what may be the reason for the increase in the average electricity consumption in (3) above?

In the extract they are trying to attend to what the questions are asking them to do but they are also dealing with the issue of language - what language to give the answer in. The extract suggests that the struggle with questions in this instance is worsened by their struggle first with understanding what the problem is asking them to do and second with finding the Tshivenda words to use.

1. Given: Di ya benefita. Hapfa neh, kha summer, kha winter vha badhela seven hundred neh, kha townhouse. Then kha...kha mudi kha winter, kha botshibadhela one-fifty two, kha botshibadhela vhugai, one-forty. So vha benefitha ngavhugai? The amount... [They benefit. Here, in summer... in winter they pay seven hundred for the townhouse. Then the household in winter they pay one-fifty two, and in summer how much do they pay, one-forty. So, how much do they benefit? The amount...]

2. Patience: (Interrupts Given) Eya, mara I think vha budzisa huri vha kho inkhriza ngavhugai. Apfa vhobadhela one-fifty two and apfa summer vha kho vhadela one-forty. [Yes but I think what is being asked is by how much will it increase. Here they pay one-fifty two and here in summer they pay one-forty.]

3. Given: Ndikhongwala nga Tshivenda zwino. [I am now going to write in Tshivenda.]

4. Sipho: Eya, ngwala nga Tshivenda ngwananga [Yes, write in Tshivenda baby!]

5. Given: (Writes in tasksheet) Ndikhoneta nga English. Ritshi... kana ndimini $u$...u...u... [I am tired of English. We say... by the way what is to...to...to...]

6. Sipho: Khezwo! ngwala nga English [Aha! write in English.]

7. Given: Hae, kana ndimini $u \ldots$ [No, by the way what is to...]

8. Patience: Kwitani [To do what?]

9. Sipho: Inkhriza [To increase?] 
10. Given: kutanga... kutanganisa, tshitangadzisa mudi kha...kha summer na mudi kha winter, ritshi mini? Mudi... Hu tanganisa ndimini ngaTshivenda [To add... to add, we add the household in... in summer and in winter, what do we say? Household... What is to 'tanganisa' (add) in Tshivenda?]

11. Patience: Ndingutanganisa [Is to ‘tanganisa' (add).]

During this interaction, language was made visible by Given in utterance 3 when she indicated that she is going to write the answer in Tshivenda. Until then language had been a transparent resource in the group as their focus was on providing answers to the questions in the task. By making language visible Given moved the learners' attention from the mathematical content of the task to the language. As we can see, from utterance 5, Given indicates that she is now going to write the answer in Tshivenda because she is "tired of English". This was responded to by Sipho in a seemingly sarcastic manner in utterance 4 by saying "yes, write in Tshivenda baby!" It is the inclusion of the word "baby" which suggests sarcasm in Sipho's tone. In utterance 6 Sipho responds to Given's struggle for a Tshivenda word for increase by saying "Aha! write in English". The inclusion of the word "aha!" in this case suggests that Sipho knew that Given would not be able to write the answer in Tshivenda. It is important to remember that these learners study their home languages as subjects at first language level. However, doing mathematics, which includes reading-writing-speaking-listening mathematically is something that they have never done in their home languages but only in English despite their limited fluency in it. So the challenge that Given is experiencing here is about doing mathematics in Tshivenda only, a constraint that she imposed on herself as Terence did not force them to give their solutions in their home languages only. According to Terence's instructions their answer would have still been accepted if it were given in English or in a mixture of English and Tshivenda.

In utterance 9 Sipho gives the transliterated word for increase, which is inkhriza, however Given does not accept it as he is looking for a pure Tshivenda term for increase. In utterance 11 Patience offers "tanganisa", this means 'add' and not 'increase'. The word for 'increase' in Tshivenda is 'huengedza', which literally means 'to make more'. It is evident from these learners' interactions in the above extract that even if learners know the answer, if they do not have the words to express it then their answer may never be known. It needs to be noted that while these learners wanted to respond to the question in Tshivenda only, it was neither necessary nor required. With the invisibility of language, it is possible that these learners may not have felt the need to respond in one language only. They could have used both Tshivenda and English to write their answer. By insisting on using only Tshivenda, language was no longer an invisible resource but an obstacle they needed to overcome by for example, finding the pure Tshivenda term for increase to use in their response to the question.

It is important to note what precipitated this visibility of language in the extract above. In utterance 5 Given indicated that she is "tired of English". But why is Given tired of English? Why does she feel empowered to express her feelings against English now when they are supposed to be solving a problem? We raise these questions here not to answer them but to signal our view that the use of language as a transparent resource is not necessarily achieved overnight especially in multilingual classrooms such as in South Africa where the political role of language both historically and in the current practices cannot be ignored. In the section that follows we explore language as a transparent resource in the learners' reflections on the lessons.

\section{Language as a transparent resource in the learners' reflections on the lessons}

As indicated earlier, reflective individual interviews were conducted with learners after the first week of lessons. Terence selected four learners from different home language groups for interviewing so as to get their reflections on the lessons observed. The interviews were semistructured and were conducted by Mampho Langa (the third author) who used to be the head of the mathematics department in the school. We decided that Mampho conduct the interviews because we thought that the learners would be free to talk frankly about their experiences of the lessons. In our view Mampho was the best person to conduct the interview also because she was not part of the team that collected the lesson observation data. Furthermore the learners were not only familiar with her but also with her position as head of the mathematics department and thus comfortable about talking with her about their mathematics learning. Learners selected languages they wanted to be interviewed in. The interviews were video recorded and then transcribed. 
In analysing the learner interviews we again looked at what was visible, i.e. presences (what the learners were talking about) and what was invisible, i.e. absences (what they were not talking about). We expected that the two main changes that we introduced (language and nature of the task) would be most visible in what the learners talk about during the interviews. In the extracts below from interviews with individual learners the interviewer asked them the same open question about what was happening in their class:

Mampho: I understand this week you had visitors in your class, what was happening?

Sindiswa: Er..., we were learning a lesson in which we can calculate electricity er .... amount ... er ... the way in which the electricity department can calculate the amount of electricity unit per household.

Nhlanhla: We were learning about how to calculate ...er...er... kilowatts of the electricity, how do we ... like ... how can we calculate them and when ... at ..., Besifunda mem ukuthi ugesi udleka kakhulu nini.

[We were learning about when there is high electricity consumption.]

Colbert: Er ...we were just solving for electricity, kilowatt per hour, for comparing if they are using card or the meter, which is both, I think are the same.

Sipho: Er, the visitors they were doing research. Gošho gore ba sheba gore bothata ... bothata ba rona bo mo kae, ka ... ka ... maths, then they found out that er... ba bang ha ba understende dilanguage, like English so, then ha ba botsa karabo then they can't find the answer. So Mr Molefe then decided to ... to ... make it in ... in English and vernacular language to ... to ..., for us to understand.

Three of the learners above point to the mathematical task that they were working on during the lesson thus suggesting that is what they found as central to what was happening during the lesson. As explained earlier, the strategy we are exploring in this class centres around two principles: (1) the deliberate use of the learners' home languages, and (2) the selection of interesting and challenging mathematics tasks. Given these principles we had thought the use of the learners' home languages in the tasks given would be the most prominent thing for the learners to notice. We thought so because language is often referred to as one of the main constraints in teaching and learning mathematics in multilingual classrooms. What is emerging in the extracts above is that for the learners the context of the task, cost of electricity, was more prominent.

Given our expectation that the learners would point to language as most prominent about what was different about the lessons, Mampho probed further as below:

Mampho: But what was so special about the lessons?

Sindiswa: It does not include those maths ... maths. It is not different, but those words used in Maths didn't occur, didn't occur but we weren't using them. ... Er ... 'simplifying', 'finding the formulas', 'similarities', ...

Nhlanhla: Hayi, no mem, ku-different... Okokuqala mem, ilokhuza, la sidila ngama-calculations awemali, manje ku-maths asisebenzi ngemali. [No mam, it is different. Firstly mam, we were working with money and usually in maths we do not work with money.]

Colbert: Iya, basenzele in order to ... ukuthi ibe simple and easy to us, because most of people, uyabona, aba-understendi like $i$... like $i$-card ne meter. Abanye bathi i-meter is ... i-price yakhona $i$-much uyabona, $i$-card iless $i$-price yakhona, that's why uyabona. So, abantu abana-knowledge, uyabona, bakhuluma just for the sake of it. So, I think for us, because we have learnt something, both are the same. [Yes, you see they made it easy for us, because most people do not understand, like card or using a meter. Some say when using the card you pay less than when using the meter, you see. So people do not have knowledge out there, they just talk for the sake of it. So I think, for us we have learnt something, both are the same.]

Sipho: Gošho gore ba sheba gore bothata ... bothata ba rona bo mo kae, ka ... ka ... maths, then they found out that er... ba bang ha ba understende dilanguage, like English so, then ha ba botsa karabo then they can't find the answer. So Mr Molefe then decided to ... to ... make it in ... in English and vernacular language to ... to ..., for us to understand. [They were looking at the problem... where our problem is, with... with... maths, then they found that er ... some of us do not understand languages like English, so when they ask for the answer we can't find it. So Mr. Molefe then decided to... to ... make it in English and vernacular language to ... to... for us to understand.]

In responding to Mampho's question above, both Sindiswa and Sipho point to language. Sindiswa points to how the task differs from the textbook tasks that they are used to. Sindiswa says of the observed lesson, that the absence of many of the 
terms usually associated with the mathematics classroom was significant, even though the essence of the lesson and activity remained unchanged. It is evident that for Sindiswa language played a clear role in the "feel" of the lesson. This is echoed by Sipho, whose response and choice of language is very interesting. What stood out for him about the lessons was what the introduction of learners' home languages allowed learners to do. It changed the dimensions of the interaction, increased participation and intervened at the level of meaning. Noticeably, he does not say "ha ba botsa karabo then they don't know the answer" ["when they ask for the answer they don't know the answer"], he says "ha ba botsa karabo then they can't find the answer" ["when they ask for the answer they can't find the answer"]. In Sipho's analysis, the learners may have the answer in one language, but their inability to find it in another language (English) has direct effects on their participation and performance.

On the face of it, Sindiswa and Sipho address different aspects of the changed lesson. However, both highlight the manner in which the use of language (or the absence of certain kinds of language) can either enable comprehension or constrain learning. Both see the actual mathematical activity as unchanged. For Sindiswa, when "difficult" words are minimised, then learners and teachers can get on with the usual business of mathematics, focusing on the task and allowing learners to experience mathematics differently and more fluently.

Nhlanhla and Colbert point to the nature of the task. For Nhlanhla what stood out the most is the fact that in mathematics they usually do not deal with calculations involving money and so these lessons were special because they involved money calculations. This resonates with Colbert's focus on the value of the task beyond the lesson. For him it was about clarifying a real life situation that he never understood - the fact that the cost for electricity will ultimately be the same in both costing structures. What Colbert is referring to is his learning about two different costing systems for electricity as described in the problem. In his view both options end up costing the same. While Colbert's analysis of the task is mathematically incorrect, it is clear that the context of the task presented a real life problem that, as he says, people in his neighbourhood have been arguing about. Looking at the graphs below illustrating the cost of electricity for the two options, it is clear that they intersect at the point $(800,200)$, which means that if electricity consumption is more than $800 \mathrm{kWh}$ then the cost of electricity will be cheaper when using the first costing structure.

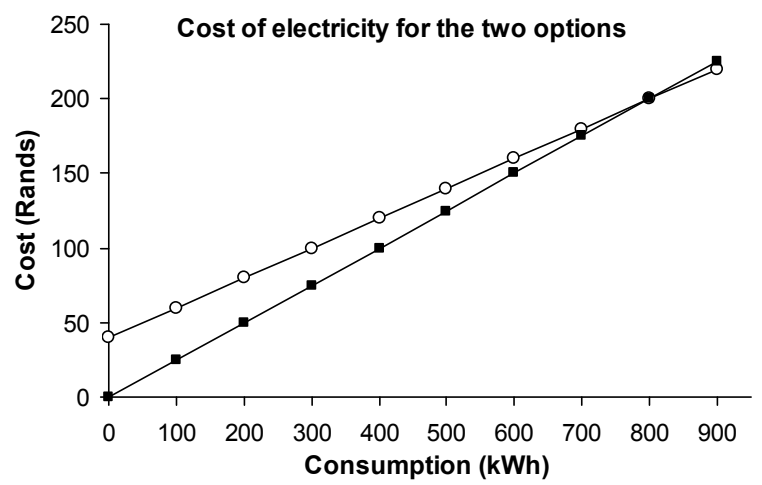

Given the learners' seeming reluctance to talk about the fact that their home languages were used, Mampho asked them a direct question about the way in which their home languages were used in the task:

Mampho: I understand that the tasks that were given were written in both your home language and English. Tell me about that.

Sindiswa: It was fine. It was just the same. It was the same as doing it in English, because I understand both languages.

Nhlanhla: I think mem leyo kusinikeza amaphepha o itwo kuya nceda mem, ngoba, like mina, kukhona amanye ama-questions bengingawaunderstandi, i-home language iyakhona ukusiza ukuthi ngiwa understande.

[Mam I think that one of giving us tasks in two languages is very helpful mam, because like there are questions that I did not understand and my home language helped me understand.]

Colbert: Iya, I think is a good idea, uyabona, ngoba iyenza ukuthi ... iyenze izinto zibe simple, ngoba if singa-understendi ngeEnglish, sicheka ku ... our languages, aba simple bese siyakhomphera.

[Yes, I think it is a good idea, you see it makes things simple because if we do not understand in English we check in our home languages and it is simple because we can compare.]

Sipho: Iya, I did understand in English and vernac. I did benefit.

From the learners' responses above it is clear that none of them experienced the use of their home languages as a distracter or constraint. In fact Nhlanhla and Colbert explained that having their home language versions was helpful. The silences and presences in the learner interviews are interesting. We find it interesting that the 
interviewer had to explicitly raise the issue of language for the learners to talk about it. This to us suggests the transparency of language as a resource. While the home languages were visible in the sense that the learners were for the first time given written text during the mathematics lessons in their home languages, they are also invisible in that they are not distracting the learners' attention from the mathematics tasks they are doing. The learners are not focusing on the languages but on the mathematics of the task. As Lave and Wenger (1991) argue, for a resource to be useful it needs to be both visible and invisible. In their view the invisibility is in the form of unproblematic interpretation and integration (of the artefact - in this case the translated versions of the task) and visibility in the form of extended access to information. While the unusual use of the learners' home languages in the task can be noticed and used, when invisible, it did not distract learners from the task. The learners were at liberty to choose which language version they wanted to refer to at any time. This, we argue, contributes to the relevance of the strategy we are exploring. The learners are given an opportunity to draw on the linguistic resources they have, and at the same time the presence of English assures them of the fact that they are not loosing access to the language of power, which they so much want to gain access to.

\section{Conclusion}

Mathematics education begins in language, it advances and stumbles because of language, and its outcomes are often assessed in language. (Durkin, 1991, p 3)

The above quotation captures the important role of language as a resource in the teaching and learning of mathematics. While it is a resource that can help advance mathematics learning, it can also be a stumbling block for successful learning. The major challenge in multilingual classrooms in South Africa is the fact that while the power of English is unavoidable, many learners do not have the level of fluency that enables them to engage in mathematical tasks set in English. In this paper we have explored a strategy for using language as a transparent resource in the teaching and learning mathematics in multilingual classrooms. This strategy is guided by two main principles - the deliberate, proactive and strategic use of the learners' main languages and the selection of real life, interesting and high cognitive demand mathematics tasks. Our analysis shows that with this strategy language becomes a visible but invisible resource in the sense that while learners can draw on different languages at any time they want, language is also invisible because it does not disturb their focus on the mathematics. We argue that our proposed strategy recognizes the political nature of English and thus while it draws on the learners' home languages, it does not present them as being in opposition to English but as working together with English to make mathematics more accessible $t$ the learners.

Through our exploration of this strategy in this study, we became more and more aware of the challenge of translating tasks into multiple languages. Translation is never a straight-forward enterprise, it is complex. As multilingual speakers of languages from different conceptual worlds we know from experience of living in language, what monolinguals know theoretically from training, that much loss and distortion of meaning can occur in translation. Yet translation is part of how meaning is transferred, made and re-negotiated; therefore, this aspect of linguistic activity remains an important consideration. This is why the deliberate, proactive and strategic use of the learners' home languages pedagogically is so important. Much remains to be done!

\section{Acknowledgements}

The work presented in this paper was supported by a grant from the National Research Foundation (TTK2007051500040). Any ideas expressed are, however, those of the authors and therefore the National Research Foundation does not accept any liability. We are grateful to the learners in Terence's class as well as the school management for agreeing to participate in this study.

\section{References}

Adendorff, R. (1993). Code-switching amongst Zuluspeaking teachers and their pupils. Language and Education, 7(3), 141-162.

Adler, J. (1998). A language of teaching dilemmas: Unlocking the complex multilingual secondary mathematics classroom. For the Learning of Mathematics, 18, 24-33.

Adler, J. (2001). Teaching mathematics in multilingual classrooms. Dordrecht: Kluwer Academic Publishers.

Arthur, J. (1994). English in Botswana primary classrooms: Functions and constraints. In C. M. Rubagumya (Ed.), Teaching and researching language in African classrooms. Clevedon: Multilingual Matters.

Baker, C. (1993). Foundations of bilingual education and bilingualism. Clevedon: Multilingual Matters. 
Clarkson, P. C. (1991). Bilingualism and mathematics learning. Geelong: Deakin University Press.

Dawe, L. (1983). Bilingualism and mathematical reasoning in English as a second language. Educational Studies in Mathematics, 14(1), 325-353.

Department of Education (1997). Language-ineducation policy. Pretoria: Department of Education.

Durkin, K. (1991). Language in mathematical education: An introduction. In K. Durkin \& B. Shire (Eds.), Language in mathematical education: Research and practice (pp. 1-3). Milton Keynes: Open University Press.

Granville, S., Janks, H., Joseph, M., Mphahlele, M., Ramani, E., \& Watson, P. (1998). English without $\mathrm{g}(\mathrm{u})$ ilt: A position paper on language in education policy for South Africa. Language in Education, 12(4), 254-272.

Grosjean, F. (1985). The bilingual as a competent but specific speaker-hearer. Journal of Multilingual and Multicultural Development, 6(6), 467-477.

Gutstein, E. (2003). Teaching and learning mathematics for social justice in an urban, Latino school. Journal for Research in Mathematics Education, 34, 37-73.

Howie, S. J. (2003). Language and other background factors affecting secondary pupils' performance in mathematics in South Africa. African Journal of Research in Mathematics, Science and Technology Education, 7, 1-20.

Howie, S. J. (2004). A national assessment in mathematics within international comparative assessment. Perspectives in Education, 22(2), 149-162.

Khisty, L. L. (1995). Making inequality: Issues of language and meaning in mathematics teaching with Hispanic students. In W. G. Secada, E. Fennema, \& L. B. Abajian (Eds.), New directions for equity in mathematics education. Cambridge: Cambridge University Press.

Lave, J., \& Wenger, E. (1991). Situated learning: Legitimate peripheral participation. Cambridge: Cambridge University Press.

Martin-Jones, M. (1995). Code-switching in the classroom: Two decades of research. In L. Milroy \& P. Muysken (Eds.), One speaker, two languages (pp. 90-112). Cambridge: Cambridge University Press.

Merritt, M., Cleghorn, A., Abagi, J. O., \& Bunyi, G. (1992). Socialising multilingualism: Determinants of code-switching in Kenyan primary classrooms. Journal of Multilingual and Multicultural Development, 13(1 \& 2), 10-121.

Moschkovich, J. (1996). Learning in two languages. In L. Puig \& A. Gutierezz (Eds.), Proceedings of the 20th Conference of the International Group for the Psychology of Mathematics Education (Vol. 4, pp. 27-34). Valencia: Universitat De Valencia.
Moschkovich, J. (1999). Supporting the participation of English language learners in mathematical discussions. For the Learning of Mathematics, 19(1), 11-19.

Moschkovich, J. (2002). A situated and sociocultural perspective on bilingual mathematics learners. Mathematical Thinking and Learning, 4, 189212.

Ncedo, N., Peires, M., \& Morar, T. (2002). Codeswitching revisited: The use of languages in primary school science and mathematics classrooms. Paper presented at the Tenth Annual Conference of the Southern African Association for Research in Mathematics, Science and Technology Education. Durban.

Rakgokong L (1994) Language and the construction of meaning associated with division in primary mathematics. Paper presented at the 2nd Annual Meeting of the Southern African Association for Research in Mathematics and Science Education.

Sachs, A. (1994). Language rights in the new constitution. Cape Town: South African Constitutional Studies Centre, University of the Western Cape.

Secada, W. (1992). Race, ethnicity, social class, language and achievement in mathematics. In D. A. Grouws (Ed.), Handbook of research on mathematics teaching and learning (pp. 623-660). New York: NCTM.

Setati, M. (1998). Code-switching in a senior primary class of second language learners. For the Learning of Mathematics, 18(2), 114-160.

Setati, M., \& Adler, J. (2000). Between languages and discourses: Language practices in primary multilingual mathematics classrooms in South Africa. Educational Studies in Mathematics, 43, 243-269.

Setati, M. (2005). Teaching mathematics in a primary multilingual classroom. Journal for Research in Mathematics Education, 36(5), 447-466.

Setati (in press). Power and access in multilingual mathematics classrooms in South Africa. South African Journal of Education.

Stein, M., Smith, M., Henningsen, M., \& Silver, E. (2000). Implementing standards-based mathematics instruction: A casebook for professional development. Reston: NCTM.

Stephens, M., Waywood, A., Clarke, D., \& Izard, J. (Eds.) (1993). Communicating mathematics: Perspectives from classroom practice and current research. Victoria: Australian Council for Educational Research.

Science in Africa (2003). Why don't kids learn maths and science successfully? Retrieved 10 April 2007 from http://www.scienceinafrica.co.za/2003/june/maths.htm

Zepp, R. (1989). Language and mathematics education. Hong Kong: API Press. 